\title{
A nationwide, resident-led teaching programme for medical students in Singapore: SingHealth Student Internship Programme Bootcamp
}

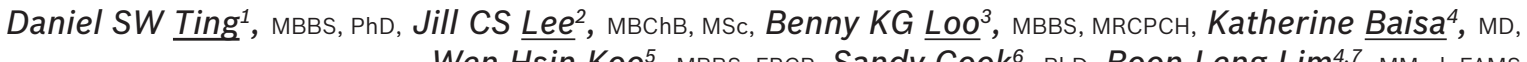
Wen $\mathrm{H} \sin \mathrm{KoO}^{5}$, MBBS, FRCP, Sandy $\underline{\mathrm{Cook}}^{6}$, PhD, Boon Leng $\underline{\mathrm{Lim}}^{4,7}$, MMed, FAMS

INTRODUCTION This study aimed to describe the planning, development and evaluation of the success of the first nationwide, resident-led, large-group teaching programme for medical students - the Singapore Health Services Student Internship Programme (SIP) Bootcamp.

METHODS This was an initial feasibility study evaluating a half-day teaching boot camp initiated, developed and conducted by the resident educators. A three-month preparation period was required to set up an education subcommittee, liaise with medical student leaders, recruit resident educators, meet all the stakeholders and conduct the boot camp. During the SIP Bootcamp, resident educators conducted clinical case presentations using a question-and-answer format. Audience participation was strongly encouraged. A 15-item questionnaire was distributed to assess the participants' learning experience and the resident educators' teaching performance using a five-point Likert scale.

RESULTS Overall, 94.8\% ( $n=110)$ of the 116 respondents agreed that the teaching sessions were of high quality and content was relevant to their training. The resident educators appeared well-informed $(96.6 \%, n=112)$ and enthusiastic about their respective topics $(98.3 \%, n=114)$. However, a few students $(9.5 \%, n=11)$ felt that the audio-visual aids and handouts could be improved to better aid their learning process.

CONCLUSION This teaching boot camp for medical students was the first of its kind in Singapore and feedback from medical students showed that it was well-received. Further research using different teaching methods, including smallgroup discussions and surgical practical sessions by resident educators from different specialties, would be of great value to students.

Keywords: resident-led medical student teaching, teaching boot camp, teaching programme

\section{INTRODUCTION}

In 2010, Singapore switched from the British-based postgraduate medical training system (basic and advanced specialty training) to the American-based residency system under the Accreditation Council for Graduate Medical Education International (ACGME-I). All three sponsoring institutions including Singapore Health Services (SingHealth), the National University Health System and National Healthcare Group made this switch. Under the ACGME-I framework, all residents are expected to achieve competence in the following six core competencies: (a) patient care; (b) medical knowledge; (c) interpersonal and communication skills; (d) professionalism; (e) practice-based learning and improvement (PBLI); and (f) system-based practice. ${ }^{(1)}$ As part of the PBLI component, all residents are expected to acquire essential teaching skills in order to improve in the areas of teaching and patient care. ${ }^{(1)}$

It is crucial to cultivate a strong teaching culture among residents early in their career. This may help improve their leadership and problem-solving skills through the discussion of case scenarios with medical students. ${ }^{(2)}$ Contrary to the commonly held perception that attending physicians are better suited to teach medical students, residents believed that teaching was integral to their training and resident-led teaching was beneficial to medical students, especially in the context of a busy clinical setting. ${ }^{(3)}$ Teaching in the clinical setting, small-group tutorials and large-group didactic sessions enable the residents to reinforce previously learnt information. In addition, teaching helps medical students to apply their theoretical knowledge to a clinical setting. Medical students are also generally more satisfied with their clerkship experience as they find it easier and more accessible to learn from resident educators in the hospital setting. ${ }^{(4)}$ In the United States, a five-day surgical boot camp for senior medical students was shown to have improved young doctors' selfconfidence in many areas of perioperative care, particularly in high-risk, infrequently performed technical tasks. ${ }^{(5)}$ Furthermore, a boot camp is also an effective way to assess residents' needs during the early phase of their residency training. ${ }^{(6)}$ In Scotland, near-peer teaching programmes were set up by a group of junior doctors to help facilitate practical and small-group teaching for medical students. ${ }^{(7)}$ With adequate training, junior resident educators can be a ready resource for teaching relevant bedside material to medical students. ${ }^{(8)}$

At present, there are three medical schools in Singapore, namely the National University of Singapore Yong Loo Lin

\footnotetext{
${ }^{1}$ Singapore National Eye Centre, ${ }^{2}$ Department of Obstetrics and Gynaecology, ${ }^{3}$ Department of Paediatric Medicine, KK Women's and Children's Hospital, ${ }^{4}$ Graduate Medical Education Office, ${ }^{5}$ SingHealth Education Office, ${ }^{6}$ Office of Education, Duke-NUS Medical School, ${ }^{7}$ Department of Anesthesiology, Singapore Health Services (SingHealth), Singapore

Correspondence: Dr Daniel Ting, Senior Resident, Ophthalmology, Singapore National Eye Centre, 11 Third Hospital Avenue, Singapore 168751.daniel.ting45@gmail.com
} 
School of Medicine (NUS Medicine), Duke-National University of Singapore (Duke-NUS) Medical School and Lee Kong Chian School of Medicine. All medical students in Singapore spend their final year of medical school in the student internship programme (SIP), which rotates them to the different major specialties (e.g. internal medicine, general surgery, obstetrics and gynaecology, paediatrics, etc). The medical student functions as an intern and is part of the medical or surgical team during this 'preinternship' year.

Traditionally, residents conduct ad-hoc tutorial sessions based on the medical students' requests, in addition to formal teaching provided by lecturers in the university and hospital setting. Previous informal feedback reported that, as the residents were generally very approachable, medical students felt that they could learn well in the more comfortable and less fearful environment. Nevertheless, the teaching faculty or programme directors did not vet the teaching content and no formal documentation of the medical students' experience during these teaching sessions was available. Hence, the Education Subcommittee of the SingHealth Residents' Committee decided to spearhead an inaugural nationwide, resident-led, largegroup teaching programme for medical students in Singapore. The purpose of our study was to describe the planning, development and evaluation of the success of the nationwide SIP Bootcamp. This teaching boot camp is an interactive teaching initiative that aimed to improve medical students' knowledge of the management of real patients during their clinical training and hone the teaching skills of resident educators.

\section{METHODS}

The nationwide, half-day teaching programme was organised for medical students of NUS Medicine and Duke-NUS in 2013. The four-hour boot camp took place at Singapore General Hospital, SingHealth, Singapore, and covered major surgical specialties such as general surgery, obstetrics and gynaecology, orthopaedics, and paediatric medicine.

Preparation for the boot camp started approximately three months prior to the actual day and was led by the head of the Education Subcommittee of the SingHealth Residents' Committee. Numerous stages of planning were required in order to maximise the experience of both the learners and teachers, and therefore ensure the success of the teaching boot camp. The stages included: (a) setting up an education subcommittee; (b) liaising with medical student leaders; (c) recruiting resident educators; (d) organising a meeting with all the stakeholders; and (e) organising the boot camp on the actual day. The Education Subcommittee comprised ten resident educators of different subspecialties, such as ophthalmology, family medicine, anaesthesia and those previously mentioned. These members were chosen by the head of the Education Subcommittee based on their previous education track record, as provided by their respective programme directors. Six resident educators were involved in the teaching boot camp, whereas the remaining four residents were involved in logistical and administrative matters.

After setting up the organising committee, the specialties to be included in the boot camp were decided. Internal medicine
Table I. Topics delivered by individual resident educators from paediatric medicine, obstetrics and gynaecology, general surgery, and orthopaedics.

\begin{tabular}{ll}
\hline Specialty & Topics \\
\hline Paediatric medicine & $\begin{array}{l}\text { A child with respiratory distress } \\
\text { Management of seizures in a child }\end{array}$ \\
$\begin{array}{l}\text { Obstetrics and } \\
\text { gynaecology }\end{array}$ & $\begin{array}{l}\text { Approaches to the first call in a labour } \\
\text { ward } \\
\text { Obstetric vaginal examination } \\
\text { Postnatal assessment } \\
\text { Management of preeclampsia } \\
\text { Management of postpartum haemorrhage } \\
\text { Management of abdominal pain with } \\
\text { electrolyte abnormalities } \\
\text { Management of trauma } \\
\text { Advanced trauma life support } \\
\text { Interpretation of limb and cervical } \\
\text { radiography }\end{array}$ \\
\hline
\end{tabular}

was not included as part of the programme, as its teaching programme was conducted separately by internal medicine residents in the small-group tutorial format. We selected three surgical disciplines and paediatric medicine based on student leaders' requests. Student leaders from both NUS Medicine and Duke-NUS felt that their curriculums were generally welldeveloped and -designed, but that the boot camp would be a beneficial platform for them to learn various case-based scenarios from the resident educators.

The resident educators, selected from their respective specialties (obstetrics and gynaecology, paediatric medicine, general surgery, and orthopaedics), were all identified as top performers in their specialties based on recommendations from their programme directors. They were required to develop and prepare their teaching plan, content and materials, then discuss the teaching content with core faculty and programme directors. These measures were taken to ensure the delivery of highquality teaching and avoid teaching medical students incorrect information. Resident educators were each allocated one hour to deliver their topics, so as to avoid overwhelming the medical students with too much information, as well as train residents to deliver focused presentations of the most salient points about each condition. The topics selected by the resident educators and their respective programme directors focused primarily on the recognition of 'red flags' and management of surgical and paediatric emergencies (Table I). They felt that medical students should know how to handle these conditions well by the end of their clinical rotation. The most suitable date for both the medical students and resident educators was chosen to maximise the participation rate.

Help was sought from the Graduate Medical Education (GME) Office for the booking of the venue, event publicity, and catering of food and beverages. An electronic poster was designed and disseminated through the medical students' portal in both NUS Medicine and Duke-NUS. The teaching boot camp was optional and open to medical students from all three medical schools. 
Table II. Feedback from medical students on the teaching content of the Student Internship Programme Bootcamp $(n=116)$.

\begin{tabular}{|c|c|c|c|c|c|}
\hline \multirow[t]{2}{*}{ Question } & \multicolumn{5}{|c|}{ No. (\%) } \\
\hline & Strongly disagree & Disagree & Neutral & Agree & Strongly agree \\
\hline The content was at an appropriate level & 0 & 0 & $4(3.4)$ & $66(56.9)$ & $46(39.7)$ \\
\hline The content was relevant to my training & 0 & 0 & $6(5.2)$ & $56(48.3)$ & $54(46.6)$ \\
\hline There was a clear introduction to the subject & 0 & 0 & $8(6.9)$ & $70(60.3)$ & $38(32.8)$ \\
\hline The aims and objectives were clearly stated & 0 & 0 & $6(5.2)$ & $74(63.8)$ & $36(31.0)$ \\
\hline $\begin{array}{l}\text { There was a clear summary and conclusion for every } \\
\text { teaching session }\end{array}$ & 0 & 0 & $9(7.8)$ & $66(56.9)$ & $41(35.3)$ \\
\hline
\end{tabular}

Table III. Feedback from medical students on the teaching performance of the residents $(n=116)$.

\begin{tabular}{|c|c|c|c|c|c|}
\hline \multirow[t]{2}{*}{ Question } & \multicolumn{5}{|c|}{ No. (\%) } \\
\hline & Strongly disagree & Disagree & Neutral & Agree & Strongly agree \\
\hline The presenters appeared well-informed about their topics & 0 & 0 & $4(3.4)$ & $46(39.7)$ & $66(56.9)$ \\
\hline The presenters appeared enthusiastic about the subject & 0 & 0 & $2(1.7)$ & $51(44.0)$ & $63(54.3)$ \\
\hline Audience participation and interaction was encouraged & 0 & 0 & $7(6.0)$ & $54(46.6)$ & $55(47.4)$ \\
\hline There was effective use of audio-visual aids/handouts & $1(0.9)$ & $1(0.9)$ & $9(7.8)$ & $65(56.0)$ & $40(34.5)$ \\
\hline The presentation was given at the right pace & 0 & $1(0.9)$ & $3(2.6)$ & $69(59.5)$ & $43(37.1)$ \\
\hline
\end{tabular}

Table IV. Feedback on the medical students' overall experience with the Student Internship Programme $($ SIP) Bootcamp $(\mathrm{n}=116)$.

\begin{tabular}{|c|c|c|c|c|c|}
\hline \multirow[t]{2}{*}{ Question } & \multicolumn{5}{|c|}{ No. (\%) } \\
\hline & Strongly disagree & Disagree & Neutral & Agree & Strongly agree \\
\hline The duration of the SIP Bootcamp was appropriate & 0 & $3(2.6)$ & $7(6.0)$ & $62(53.4)$ & $44(37.9)$ \\
\hline $\begin{array}{l}\text { The SIP Bootcamp provides me with useful cases that will } \\
\text { help me in my future training as a medical doctor }\end{array}$ & 0 & 0 & $6(5.2)$ & 59 (50.9) & $51(44.0)$ \\
\hline $\begin{array}{l}\text { The administrative arrangements } \\
\text { (e.g. training venue and catering) were appropriate }\end{array}$ & 0 & 0 & $3(2.6)$ & $56(48.3)$ & 57 (49.1) \\
\hline Overall, the teaching sessions were of a high quality & 0 & 0 & $6(5.2)$ & $54(46.6)$ & $56(48.3)$ \\
\hline
\end{tabular}

On the day of the boot camp, resident educators conducted didactic lectures in combination with interactive sessions. Audience participation was strongly encouraged throughout the whole session. At various points during the case presentations, resident educators would actively engage the students by questioning them on history taking and clinical examination technique. In addition, the students were asked to interpret blood test results and imaging results (radiographs of the chest and abdomen and computed tomography scans of the abdomen); they were also asked to present a diagnosis and appropriate management plan.

At the end of the boot camp, the students were given a questionnaire on the residents' teaching performance, appropriateness of the content and quality of the teaching programme. The feedback questionnaire consisted of 15 questions on a five-point Likert scale ( 1 = strongly disagree, 5 = strongly agree). All data was analysed using SPSS Statistics version 17.0 (SPSS Inc, Chicago, IL, USA). This study was conducted in accordance with the Declaration of Helsinki, with an exemption for ethics approval from the SingHealth Institutional Review Board.

\section{RESULTS}

A total of 145 medical students attended the boot camp. Of these participants, $80.0 \%(n=116)$ responded to the questionnaire. Most students felt that the content was delivered at an appropriate level $(96.6 \%, \mathrm{n}=112)$ and relevant to their training $(94.8 \%$, $\mathrm{n}=110$ ). The majority agreed that the introduction, aims and objectives of the topics covered by each specialty were clearly stated, the flow of the presentation was well-organised, and there was a clear summary and conclusion for each teaching session (Table II).

The medical students generally had positive feedback on the residents' medical knowledge $(96.6 \%, \mathrm{n}=112)$ and enthusiasm $(98.3 \%, n=114)$ for their presentations (Table III). Regarding audience participation and interaction, the students agreed that they actively participated in the discussions throughout the sessions $(94.0 \%, \mathrm{n}=109) .11$ (9.5\%) medical students thought that improving the use of the audio-visual aids and handouts would enhance their learning experience, whereas 1 (0.9\%) student felt that the presentation was not given at the right pace (Table III). 10 (8.6\%) students did not agree that the duration of the boot camp was appropriate and, on further enquiry, reported that they were overwhelmed by the amount of information delivered during the entire teaching programme (Table IV). $94.8 \%(n=110)$ of respondents felt that the quality of teaching was high and most $(94.8 \%, \mathrm{n}=110)$ agreed that the boot camp had provided them with useful cases that would help with their future medical training (Table IV). Regarding the training venue, most (97.4\%, $\mathrm{n}=113$ ) found that it was convenient. 
Table V. 12 tips for running a successful resident-led programme by Mabvuure et al. ${ }^{(10)}$

1. Clearly define the scope of your programme

2. Ensure student-defined learning goals are included at an early stage

3. Inform and involve your fellow junior doctors in teaching

4. Plan teaching rota in advance

5. Learn to teach effectively by attending courses

6. Promote your programme to medical students as widely as possible

7. Use varied and interactive teaching methods

8. Establish rapport with students

9. Include assessment as part of the teaching programme

10. Seek feedback from attendees and senior faculty

11. Establish rules for tutorials

12. Secure formal recognition for your scheme

\section{DISCUSSION}

The SIP Bootcamp was the first nationwide, large-scale, residentled teaching programme for medical students in Singapore. It was a platform for residents to hone their teaching, collaboration and organisational skills, while medical students had the opportunity to learn in interactive sessions. Providing residents with sufficient depth of teaching skills is a challenge that medical schools and residencies currently face. Obstacles in administering teaching skills programmes for residents include the complexity of resident schedules, work-hour limitations and resident rotations at multiple clinical sites. ${ }^{(9)}$

Mabvuure et al recommended 12 tips to run a successful junior doctor-led teaching programme for medical students (Table V). ${ }^{(10)}$ These tips help to maximise the medical students' learning experience during the teaching programme. However, compared to Mabvuure et al, ${ }^{(10)}$ the present study simplified the planning process into the following five successive steps: (a) setting up an education subcommittee; (b) liaising with medical student leaders to ascertain topics and format of interest; (c) recruiting of resident educators from the respective specialties based on the programme director's recommendations; (d) planning of a meeting involving the education subcommittee, resident educators, medical student leaders and graduate medical education officers to finalise the date, venue, and administrative and logistics matters (printing of handouts and audio-visual aids); and (e) organisation of the boot camp on the actual day.

Undergoing the actual clinical experience or sub-internships is always the best way to increase medical students' clinical competency. The boot camp was conducted with the aim of creating an interactive question-and-answer session using casebased scenarios that simulated the real clinical environment. Due to the available resources, teaching was performed through the use of clinical case presentations. It was also considered more manageable to organise a teaching boot camp that involved six resident educators and more than 100 medical students in a large auditorium. Nevertheless, future research aims to expand the boot camp to involve more specialties using different formats (e.g. small-group discussions and practical sessions).
Our results showed that the majority of students felt that the contents of the presentations were set at an appropriate level and, most importantly, found the teachings relevant to their medical training. From the informal feedback, we found that some medical students had difficulty applying their theoretical knowledge in a clinical situation. This boot camp was structured to provide them with a simulated clinical environment, giving them the confidence and competency to manage real patients during their clinical training.

This boot camp was initiated by a group of residents from the SingHealth Residents' Committee. They developed the concept, teaching programme and logistics with the support of programme directors, faculty and the GME Office. Student leaders from both NUS Medicine and Duke-NUS were invited to give feedback during the developmental process on the content and type of learning that they felt would be useful to them and was lacking in their medical school curriculum at the time. Such collaboration between residents from various specialties and medical student leaders is not common in routine clinical medicine. The opportunity offered by the SIP Bootcamp was unique and encouraged discussion and collaboration among potential future leaders in the healthcare service.

In order to engage the medical students, the presenters were advised to prepare their slides in the format of case-based scenarios and encourage audience participation throughout their talks, as students generally find it easier to learn in an interactive environment. ${ }^{(11)}$ Medical students were given opportunities to ask questions during and at the end of each lecture, and lecture notes were distributed to them at the end of each session. The participant feedback questionnaire found that most students felt that the presentations were given at the right pace and presenters were enthusiastic about their subject; this suggests that this method of faculty-supervised development of teaching plans and content with residents is useful and facilitates the building of a successful teaching programme.

The SIP Bootcamp was a half-day, national, medical student teaching programme that ran for four hours. In Scotland, a wellestablished near-peer teaching programme involves various junior doctors as resident educators. ${ }^{(7,8)}$ It started in 2006 as one programme (73 tutorials conducted by 18 tutors) and has now expanded to four programmes (324 tutorials conducted by 108 tutors), run throughout the year and focusing on bedside teaching. This is another teaching method that we may be able to implement in the future as part of the national teaching programme for medical students.

The overall mission of the World Federation for Medical Education is to promote the highest scientific and ethical standards in medical education, initiation of new learning methods and instructional tools, and innovative management of medical education. ${ }^{(12)}$ Continuing medical education or continuing professional development (CPD) is routine in most healthcare systems around the world. CPD often implies selfdirected and practice-based learning activities to maintain and develop competencies of individual doctors. Hence, residents 
should be encouraged to engage in more teaching activities as part of CPD activities throughout their medical career.

Kirkpatrick's Learning Evaluation Model, designed to evaluate training programmes, ${ }^{(13)}$ contains the following four levels: (a) reaction - how the learners thought and felt about the teaching programme; (b) learning - the resulting increase in knowledge; (c) behaviour - application of the learning; and (d) results - the effect on the environment due to improved performance. In our study medical students were evaluated using the first level of the model. Future studies, using the model's subsequent levels, would be of great value to assess the impact of the teaching programme.

There were some limitations to our study. There was a lack of benchmark comparisons and preassessments of the needs of medical students from both universities. In addition, the academic effect of this teaching programme was not assessed. We did not compare the medical students' knowledge before and after the programme, as we did not want it to cause stress to the participants. Another limitation of the study was the lack of formal feedback from the resident educators themselves and their peers about their teaching during this programme. Selfreflection on residents' teaching experience could have been included as a formative assessment. Medical teachers should take responsibility for their personal $\mathrm{CPD}$ and regularly assess and review their own competence. ${ }^{(14)} \mathrm{A}$ longitudinal follow-up study on the subsequent teaching efforts of each of these residents can also help to build their teaching portfolio as they pursue the clinician-educator track. ${ }^{(15)}$

Even though our study found that the teaching quality was high and would be helpful to medical students' future training, this was only based on self-reported feedback. These medical students may be too junior to decide if the knowledge delivered would make any impact on their future training. Another limitation is the lack of self-assessment, as well as learner, peer and faculty assessments, of the teaching skills of the resident teachers. ${ }^{(16,17)} \mathrm{A}$ validated tool like the Stanford Faculty Development Programme (Form 26) has been widely used to evaluate the teaching knowledge, skills and attitudes of resident teachers. ${ }^{(18)}$ To improve future SIP boot camps, it would be of great value to distribute separate questionnaires to medical students and resident educators during a subsequent teaching programme to collect feedback from participants and teachers.

In conclusion, this SIP Bootcamp was the first nationwide, large-scale, medical students' teaching programme led by residents in Singapore. It is an excellent platform to foster camaraderie among residents from various specialties and medical student leaders, and to train residents to be organisers and medical educators. Even though only four specialties were covered in this boot camp, it was a good start with excellent feedback from a large number of medical students. We hope to increase the recruitment of both medical students and resident educators in the coming years.

\section{ACKNOWLEDGEMENTS}

We would like to thank all the resident educators involved in this project, including Dr Celene Hui (obstetrics and gynaecology), Dr Katrina Heng (paediatric medicine), Dr Mark Cheah (internal medicine), Dr Sim Yi Rong (general surgery) and Dr Hamid Rahmatullah (orthopaedic surgery). In addition, this boot camp would not have been successful without the financial, administrative and manpower support from the SingHealth senior management and GME Office. Last but not least, we would also like to express our sincere gratitude to the SingHealth Residents' Committee, NUS Medical Society and Duke-NUS Student Council for helping us publicise this event to residents and medical students.

The study findings were presented at the ACGME Annual Education Conference 2014 in Maryland, USA.

\section{REFERENCES}

1. ACGME-I. Foundational Program Requirements. 2012.

2. Wipf JE, Pinsky LE, Burke W. Turning interns into senior residents: preparing residents for their teaching and leadership roles. Acad Med 1995; 70:591-6.

3. Busari JO, Scherpbier AJ, van der Vleuten CP, Essed GG. The perceptions of attending doctors of the role of residents as teachers of undergraduate clinical students. Med Educ 2003; 37:241-7.

4. Wright S, Wong A, Newill C. The impact of role models on medical students. J Gen Intern Med 1997; 12:53-6.

5. Okusanya OT, Kornfield ZN, Reinke CE, et al. The effect and durability of a pregraduation boot cAMP on the confidence of senior medical student entering surgical residencies. J Surg Educ 2012; 69:536-43.

6. Fernandez GL, Page DW, Coe NP, et al. Boot cAMP: educational outcomes after 4 successive years of preparatory simulation-based training at onset of internship. J Surg Educ 2012; 69:242-8.

7. Qureshi Z, Ross M, Maxwell S, et al. Developing junior doctor-delivered teaching. Clin Teach 2013; 10:118-23.

8. Qureshi Z, Seah M, Ross M, Maxwell S. Centrally organised bedside teaching led by junior doctors. Clin Teach 2013; 10:141-5.

9. Moser EM, Kothari N, Stagnaro-Green A. Chief residents as educators: an effective method of resident development. Teach Learn Med 2008; 20:323-8.

10. Mabvuure NT, Rodrigues J, Cumberworth A, Mahmud M. Twelve tips for running successful junior doctor-led teaching programmes for medical students. Med Teach 2013; 35:628-32.

11. Silverthorn DU. Teaching and learning in the interactive classroom. Adv Physiol Educ 2006; 30:135-40.

12. World Federation for Medical Education. Continuing Professional Development (CPD) of Medical Doctors: WFME Global Standards for Quality Improvement. Copenhagen: University of Copenhagen, 2003.

13. Kirkpatrick DL, Kirkpatrick JD. Transferring Learning to Behavior: Using the Four Levels to Improve Performance. California: Berrett-Koehler Publishers, 2005.

14. Harden RM, Laidlaw JM. Essential Skills for a Medical Teacher: An Introduction to Teaching and Learning in Medicine. London: Elsevier Churchill Livingstone, 2012.

15. Jibson MD, Hilty DM, Arlinghaus K, et al. Clinician-educator tracks for residents: three pilot programs. Acad Psychiatry 2010; 34:269-76.

16. Wamsley MA, Julian KA, Wipf JE. A literature review of "resident-asteacher" curricula: do teaching courses make a difference? J Gen Intern Med 2004; 19:574-81

17. Ricciotti HA, Dodge LE, Head J, Atkins KM, Hacker MR. A novel residentas-teacher training program to improve and evaluate obstetrics and gynaecology resident teaching skills. Med Teach 2012; 34:e52-7.

18. Litzelman DK, Stratos GA, Marriott DJ, Skeff KM. Factorial validation of a widely disseminated educational framework for evaluating clinical teachers. Acad Med 1998; 73:688-95 